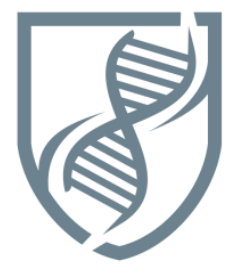

Journal of Bioscience and Applied Research

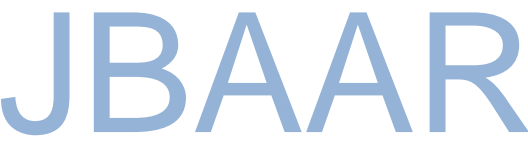

WWW.JBAAR.ORG

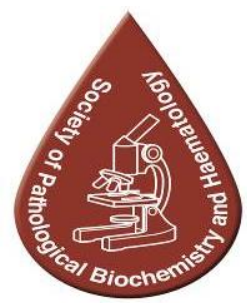

\title{
Clinical and microbiological efficacy of medicinal maggots in the treatment of
} pressure ulcers in Egypt

\author{
Tarek I. Tantawi' ${ }^{1}$, Yousry M. Gohar ${ }^{2}$, Soheir G. William ${ }^{3}$, Mamdouh M. Kotb ${ }^{4}$, \\ Nesreen A. Abou Zeid ${ }^{3}$ \\ ${ }^{1}$ Department of Zoology, Faculty of Science, Alexandria University, Alexandria, Egypt. \\ ${ }^{2}$ Microbiological Division, Faculty of Science, Alexandria University, Alexandria, Egypt. \\ ${ }^{3}$ Medical-Surgical Nursing Department, Faculty of Nursing. Alexandria University, Alexandria, Egypt. \\ ${ }^{4}$ Department of Surgery, Vascular Surgery Unit, Faculty of Medicine, Alexandria University, Alexandria, Egypt.
}

DOI: 10.21608/jbaar.2017.126133

\begin{abstract}
Pressure ulcers are a significant public health problem, especially for patients in long term care facilities. This study aimed to assess the clinical and microbiological efficacy of maggot therapy in the treatment of pressure ulcers. The study was conducted on 14 bed-bound patients with 14 pressure ulcers at Alexandria Main University Hospital, Alexandria, Egypt. The blowfly Lucilia sericata was used for maggot therapy. Each ulcer was treated by one maggot cycle of 3 days per week. The ulcers were investigated weekly for changes in their size, the size of necrotic tissue, and the bacterial burden before and after each maggot cycle. Of the 14 ulcers treated with maggot therapy, three ulcers were completely debrided of which one ulcer needed only one cycle and two ulcers were debrided by two cycles. Nine ulcers had $>50 \%$ of their size occupied by a red healthy granulation tissue during a mean period of 2.14 weeks. The mean of the initial bacterial burden of ulcers was significantly decreased from $4.86 \times 10^{8} \mathrm{CFU} / \mathrm{ml}$ exudate to $1.92 \times 10^{4} \mathrm{CFU} / \mathrm{ml}$ exudate $(p=0.01814)$ below the $10^{5}$ thresholds of natural healing after the first maggot cycle. The clinical and microbiological outcomes demonstrate that maggot therapy is a rapid, simple, efficient, and cost-effective tool for treating pressure ulcers that do not respond to conventional treatment and surgical intervention.
\end{abstract}

Keywords: maggot therapy, Lucilia sericata, pressure ulcers, Egypt 


\section{Introduction}

Pressure ulcers, one type of chronic wound, remain a significant problem in both acute and community health settings (Bergstrom et al. 1994; Whitney et al. 2006; Spilsbury et al 2007; Tachibana et al. 2016). Pressure ulcers are not a plague of modern man but have been known to exist since ancient Egyptian times and have even been identified in the remains of mummified Egyptian priestess (Hampton 2005). The impact of pressure ulcers is significant in terms of both financial and nonmonetary costs. Non-monetary costs are often described as the hidden costs of pressure ulcer care, including the emotional and physical impact on patients and their family caregivers. These patients reported a profound impact on many aspects of their lives (physical, social, financial), as well as a loss of independence and control (Dharmarajan and Ugalino 2002; Niezgoda and Mendez-Eastman 2006; Spilsbury et al. 2007; Amir et al. 2017).

A pressure ulcer is defined as any lesion caused by unrelieved pressure resulting in damage to the underlying tissue (Amir et al. 2016; Tachibana et al. 2016). The development of pressure ulcers is increased when the duration of immobility is increased. Once a pressure ulcer develops, this increases nursing care time, hospital care, infection, and mortality (Allman et al. 1995, 1999; Amir et al. 2017).
Despite the many developments in wound care, there has been no significant decrease in pressure ulcer prevalence or any demonstrable improvement in overall outcomes (Niezgoda and Mendez-Eastman 2006; Whitney et al. 2006; Amir et al 2017). New treatment paradigms must be examined as we strive to reduce pressure ulcer morbidity. For centuries, the infestation of wounds by certain species of fly larvae (maggots) has been recognized to debride, enhance healing, and decrease the mortality associated with underlying injury (Sherman et al. 2000).

The past three decades have witnessed the resurgence in the use of maggot therapy in wound management due to the recognized limits of conventional medical and surgical treatments, the increase of antibiotic resistance, and the growing data demonstrating the safety and efficacy of this simple, low-cost modality (Trudgian 2002; Thomas 2006; Sherman et al. 2013). Maggot therapy (also known as maggot debridement therapy, larval therapy, or biosurgery) is the medical use of live blowfly larvae to treat nonhealing infected wounds (Sherman et al. 2000). Maggots act in three primary ways; debriding (removal of necrotic tissue), disinfecting (killing bacteria), and promoting the production of granulation tissue (Sherman 2014; Sherman et al. 2013). 
Kotb et al. (2002) have conducted the first scientific study in Egypt on the use of medicinal maggots in the management of venous stasis and diabetic foot ulcers. Tantawi et al. (2007) have investigated the clinical and microbiological efficacy of maggot therapy for treating diabetic foot ulcers in Egypt. The outcomes of these studies have paved the way to investigate the utility of maggot therapy in the treatment of one of the most common types of chronic wounds, pressure ulcers.

The present study aims to investigate the clinical (debridement and wound healing) and microbiological outcomes of maggot therapy in the management of pressure ulcers.

\section{Materials and Methods}

\section{Patient selection}

Fourteen bed-bound adult patients with 14 sacral and ischial pressure ulcers of stage III and stage IV over 14 months were included in the study at the general medical-surgical wards, critical care units, and emergency recovery room at Alexandria Main University Hospital, Alexandria, Egypt. Permission to conduct the study was obtained from the ethical committee of the Faculty of Medicine, Alexandria University.

\section{Clinical evaluation}

Patient and wound histories were collected directly from the patients and their medical records. An initial assessment of the ulcers (site, age, and staging) was done according to NPUAP (2001). The circumferences of ulcers and necrotic tissue were determined by wound tracing and then measured by a mechanical planimeter. Ulcers were evaluated visually and photographically. Hemoglobin and albumin levels were measured.

\section{Maggot therapy protocol}

During this study, the blow fly Lucilia sericata (Meigen) (Diptera: Calliphoridae) were reared and disinfected for medical use at the Maggot Therapy and Microbiology Laboratory, Faculty of Science, Alexandria University. The method of disinfection of $L$. sericata eggs is that of Kotb et al. (2002). The maggot therapy dressing used in our study is that of Kotb et al. (2002) and Tantawi et al. (2007) (Fig.1.) Each ulcer was treated with one maggot cycle of three days per week. At the end of each cycle, maggots were removed by peeling back the dressing with one hand while wiping up the larvae with a wet gauze pad held in the other hand and then destroyed by incineration. In between maggot cycles, patients regularly received sterile saline wet-to-dry gauze dressing. Maggot cycles were regularly applied until complete $(100 \%$ of the wound bed is free from devitalized tissue) or adequate (80-90\% of the wound bed is free from devitalized tissue) 
debridement of the wound is attained within 3 months.

\section{Wound evaluation after maggot therapy}

Changes in the size of devitalized tissue and granulation tissue over time were recorded. Surface area and percentage of devitalized tissue were assessed each week. The degree of debridement was determined as the percentage of the surface area being debrided to the initial surface area of the wound. The rate of wound healing, if examined, was calculated as the average percent change (decrease) in the initial surface area of devitalized tissue of the wound per week. Wound color and odor and presence or absence of granulation tissue were recorded after each maggot cycle.

\section{Microbiological procedures}

During the present study, samples were collected from ulcers before and after each maggot cycle to investigate and to determine the bacterial load (burden), polybacterial population, and the type of bacteria in each ulcer. Sterile cotton swabs were used to collect samples from the surface and subsurface of different representative locations in the ulcers. Fully exudates-saturated swabs (each loaded with $\sim 250 \mu \mathrm{l}$ ) were taken from each ulcer and instantly immersed in LB-broth in 10-ml sterile screw-capped tubes as a transferring medium. Each tube contained sterile $2.5 \mathrm{ml}$ broth. Bacterial cells were released from the swabs by vortexing for $3 \mathrm{~min}$. to have a ten-time diluted bacterial suspension. This suspension represented a one-tenth concentration of bacteria.

A serial dilution technique was used to count the Colony Forming Units (CFU) of bacteria in the previous suspension per each swab $(250 \mu 1)$. Obtained counts were multiplied by four to give the $\mathrm{CFU} / \mathrm{ml}$ exudates which represent loads of the bacteria per $1 \mathrm{ml}$ exudates. From the dilution plates, colonies with different morphology and growth behavior isolated from different ulcers were picked up and purified by streaking on LB-agar plated before being subjected to preliminary and biochemical identification tests. Preliminary identification was done by the appearance of colonies on the agar plates.

The identification of bacteria was based upon feeding a database for the probabilistic identification program designed by Microsoft ${ }^{\circledR}$ (Bryant 2004). Gram's staining microscopic examination was done, as well as, catalase test, urease test, indole production, citrate utilization, lactose and glucose fermentation, nitrate reduction, hydrogen sulphide production, and oxidase production, as key confirmatory and differentiating tests between wound bacterial flora. The used media have been prepared according to Atlas (1997).

\section{Statistical analysis}

Differences in surface area of necrotic tissue and granulation tissue of ulcers before 
and after maggot therapy were statistically evaluated using Student's t-test (Sokal and Rohlf 1981).

\section{Results}

A group of 14 patients (10 males and 4 females) with 14 pressure ulcers was enrolled in this study. The mean age of patients was 43.35 years (range 18-81 years) (Table 1). All patients were with altered level of consciousness except only two patients were conscious. The patients were generally suffering from prolonged hospitalization with complete bedridden with a mean duration of 11.28 weeks (range 0.7-49.1 weeks). The mean albumin level was $2.54 \mathrm{~g} / \mathrm{dl}$ (range 2-3.1 g/dl) indicating that these patients were immunocompromised.

The characteristics of the 14 pressure ulcers before undergoing maggot therapy are shown in Table 2. Seven wounds were staged as stage III and the other 7 wounds were as stage IV. Ten ulcers were found on the sacrum, and 4 ulcers were on the right ischia. All the ulcers were previously treated with the conventional non-surgical methods available at Alexandria Main University Hospital; only six ulcers had undergone sharp debridement. The ulcers had a mean surface area of $90.7 \mathrm{~cm}^{2}$ (range 28.6-154 $\mathrm{cm}^{2}$ ). Necrotic tissue represented a mean of $61.73 \%$ (range 18.5-
$100 \%$ ) of the size of ulcers. The mean age of ulcers was 9.78 weeks (range 2-15 weeks).

Maggot therapy was associated with a rapid rate of debridement (Table 3, Fig. 2). Before maggot therapy, the mean surface area of devitalized tissue was $58.81 \mathrm{~cm}^{2}$ (range 8.25 $131.25 \mathrm{~cm}^{2}$ ), whereas after maggot therapy this means significantly decreased to $15.35 \mathrm{~cm}^{2}$ (range $\left.0-40 \mathrm{~cm}^{2}\right)(p=0.000307)$ during a mean period of 1.5 weeks (range 1-2 weeks). This indicated that maggots decreased the size of necrotic tissue by an average of $43.46 \mathrm{~cm}^{2}$. A mean of $27.68 \%$ decrease in size of necrotic tissue was recorded per week. The mean number of maggot therapy cycles was 1.5 (range 1-2). Three ulcers (21.42\%) were completely debrided by maggots of which one ulcer needed only one cycle and two ulcers were debrided by two cycles. Eleven patients had their ulcers not completely debrided because they died after undergoing one or two cycles of maggots. In nine ulcers (64.28\%) more than $50 \%$ of the necrotic tissue was removed of which 5 ulcers were debrided with one cycle and four ulcers needed two cycles. In two ulcers $(14.28 \%)$ less than $50 \%$ of the devitalized tissue was removed with only one cycle.

Maggot therapy was also associated with the rapid growth of granulation tissue (Table 4, Fig. 3). A red, healthy wound bed was 
noticed in all cases after maggot therapy. Before maggot therapy, the mean surface area of granulation tissue was $16.03 \mathrm{~cm}^{2}$ (range 0-80 $\mathrm{cm}^{2}$ ), whereas after maggot therapy this means significantly increased to $55.86 \mathrm{~cm}^{2}$ (range 7.37-116 $\left.\mathrm{cm}^{2}\right)(p=0.000221)$ during a mean period of 2.14 weeks (range 1-10 weeks). This indicated that maggots increased the size of granulation tissue by an average of $39.83 \mathrm{~cm}^{2}$. Nine ulcers $(64.28 \%)$ had $>50 \%$ of their size occupied by red healthy granulation tissue. Figures 4 and 5 illustrate the clinical outcomes (debridement and granulation tissue growth) of maggot therapy in two pressure ulcers.

A total of 20 bacteria were isolated from the 14 ulcers examined. These bacteria were eight Gram-positive (7 aerobic and 1 anaerobic) and 12 Gram-negative (10 aerobic and 2 anaerobic) (Table 5). All ulcers exhibited a mixed bacterial population ranged from three to seven microorganisms (Table 6).

Maggot therapy was associated with marked antimicrobial activity (Table 7). The mean initial bacterial burden was $4.86 \times 10^{8}$ $\mathrm{CFU} / \mathrm{ml}$ exudate. After the first maggot cycle, this means has significantly decreased to $1.92 \times$ $10^{4} \mathrm{CFU} / \mathrm{ml}$ exudate $(p=0.01814)$ below the $10^{5}$ thresholds of natural healing.

The maximum fold of decrease in the bacterial count was recorded in ulcer $6(2.15 \times$ 10 fold) and the minimum was observed in ulcer $12\left(4.6 \times 10^{6}\right.$ fold) (Table 7$)$. The second maggot cycle was applied to six ulcers only because eight patients had died. The mean bacterial burden of the six ulcers before the second cycle was $5.61 \times 10^{5} \mathrm{CFU} / \mathrm{ml}$ exudate. This means significantly decreased to $1.36 \times$ $10^{7} \mathrm{CFU} / \mathrm{ml}$ exudate after the second maggot cycle $(p=0.1455)$. The maximum fold of decrease in the bacterial count after the second cycle was observed in ulcer $9(4.29 \times 10$ fold $)$ and the minimum was noticed in ulcer 12 (4.44 $\times 10^{4}$ fold). It should be noted that the bacterial load of all ulcers was less than $10^{5} \mathrm{CFU} / \mathrm{ml}$ exudate after the first or the second maggot therapy cycle.

\section{Discussion}

A significant development in the area of modern wound management is the recent reintroduction of maggot therapy for treating intractable, chronic wounds (Schultz et al. 2003; Kirshen et al. 2006). Maggot therapy has been successfully used in the treatment of pressure ulcers (Sherman et al. 1995; Sherman 2002), leg ulcers of venous, arterial, or mixed origins (Sherman et al. 1996; Thomas et al. 1996; Kotb et al. 2002; Davies et al. 2015), and diabetic foot ulcers (Mumcuoglu et al. 1998; Kotb et al. 2002; Sherman 2003; Gilead et al. 2012; Mirabzadeh et al. 2017).

During this work, maggot therapy was a rapid, simple, safe, well-tolerated, and costeffective tool for the treatment of pressure 
ulcers, which did not respond to conventional treatment and surgical intervention. Maggot therapy was associated with rapid wound debridement. Complete debridement was achieved in $21.42 \%$ of the ulcers and significant debridement was achieved in $64.28 \%$ of the ulcers of the patients with one or two maggot therapy cycles. Mumcuoglu et al. (1999), working on maggot therapy on patients with leg ulcers, pressure ulcers, and other types of wounds, found that the number of cycles needed to debride these wounds varied between one and 14 (mean, 6). In a maggot therapy study on diabetic ulcers, Mumcuoglu et al. (1998) stated that the number of cycles required for treatment varied between 1 and 23 (mean, 5.7). In the present study, $8.33 \%$ of patients have their ulcers completely debrided through one maggot therapy cycle and $14.28 \%$ of patients have their ulcers completely debrided through two maggot therapy cycles. Wayman et al. (2000) had obtained complete debridement in all six venous ulcers of patients enrolled in their study through only one maggot cycle. Kotb et al. (2002) have recorded complete debridement in $95 \%$ of the 30 venous leg ulcers belonging to 20 patients after treatment with one or two maggot cycles.

Tanyuksel et al. (2005) noticed that maggots completely debrided diabetic wounds varying in size from 6-84 $\mathrm{cm}^{2}$ within 6-14 days through 1-6 cycles. Wolff and Hansson (2003) have investigated the effects of maggot therapy on wounds in an open study of 74 patients with necrotic chronic ulcers of different etiologies. They found maggot therapy to effectively debride $86 \%$ of the ulcers to between 66 and $100 \%$, and a single application or cycle was clinically beneficial in $72 \%$ of patients. They also noticed that no ulcer type was shown to be more suited to maggot therapy than others; however, ulcers in all 29 patients with diabetes were completely debrided the venous ulcers of 16 of 20 patients with one cycle only. Also, in the same study, 6 of 11 diabetic patients had their ulcers completely debrided with only one maggot therapy cycle.

During this study, a mean of $28.97 \mathrm{~cm}^{2}$ of necrotic tissue per week was removed by maggots. This represented a mean of $27.68 \%$ decrease in size of necrotic tissue per week. Sherman (2002) in his study on pressure ulcers, found that wounds treated with maggots showed a significant average decrease of 3-7 $\mathrm{cm}^{2}$ of necrotic tissue within the first 2 weeks of therapy ( $p<0.001)$. Also, in his study on diabetic foot ulcers, Sherman (2003) noticed that maggot therapy was associated with a significant decrease in necrotic tissue of a mean of $4.1 \mathrm{~cm}^{2}$ within 2 weeks $(p=0.02$ ), whereas conventional therapy was not associated with any decrease in necrotic tissue over the same period. 
Tantawi et al. (2007) investigated the debridement efficacy of maggots on 13 diabetic foot ulcers belonging to 10 patients. Complete debridement occurred in all ulcers in a mean of 1.9 weeks (range 1-4). The mean decrease in the percentage of necrotic tissue within the ulcer surface area was $64.7 \%$ (range 24.9-100) per week. Five ulcers required one cycle of maggot, five required two cycles, two required three cycles and only one ulcer needed four cycles to achieve complete debridement. After maggot therapy, the mean ulcer surface area decreased significantly from $23.5 \mathrm{~cm}^{2}$ to $2.3 \mathrm{~cm}^{2}$ $(p=0.001)$ in a mean of 8.1 weeks. This represented a mean $90 \%$ reduction in ulcer size, with a mean decrease of $16 \%$ per week.

Lucilia sericata larvae can only ingest liquid or semi-liquid food since they have no teeth within the mouth (Sherman 2014). Necrophagous species feed on the dead tissue, cellular debris, and serous drainage of corpses or necrotic wounds (Zumpt 1965). Extracorporeal digestion by means of both amylase-containing saliva and proteolytic enzymes passed off in larval excreta is one mechanism by which wounds are cleansed (Sherman 2014; Nigam 2016). Debridement is also enhanced by the maggots' crawling about the wounds, probing, and macerating it with their mouth hooks (Sherman 2014).

The results of this study have proved that maggot therapy is an effective method for initiating granulation. In a prospective controlled study to evaluate the utility of maggot therapy for treating pressure ulcers in spinal injury patients, it was found that wound healing was very rapid during maggot therapy than during antecedent conventional therapy (Sherman et al. 1995). Kotb et al. (2002) have investigated healing in 17 venous stasis ulcers belonging to 10 patients who undergone maggot therapy. The mean surface area of these ulcers before maggot therapy was $57.70 \mathrm{~cm}^{2}$, whereas after maggot therapy this means decreased to $17.19 \mathrm{~cm}^{2}(p<0.05)$ during a mean period of 2.6 weeks (range 1-5.4 weeks). This indicated a mean of $70.21 \%$ decrease in size of ulcers. The authors also recorded that the ulcers healed at a mean rate of $32.98 \%$ per week. In two retrospective controlled studies to evaluate the utility of maggot therapy for treating pressure ulcers (Sherman 2002) and diabetic foot ulcers (Sherman 2003), maggot-treated wounds had faster rates of debridement and healing than conventionally treated wounds.

Although some early researchers believed that the larvae merely facilitated the normal healing process by eliminating necrosis and infection, it has now been shown that the larval digestive juices containing growth factors that stimulate healing (Sherman et al. 2013). Many clean wounds, requiring no debridement at all, heal faster when treated with maggots (Sherman 2002, 2014). The secretory/excretory 
products of maggots contain ammonia, urea, and allantoin, which are known to stimulate granulation (Sherman et al. 2000). In addition, maggot excretions contain calcium carbonate, which changes the wound $\mathrm{pH}$ from acid to neutral or slightly alkaline ( $\mathrm{pH} 7$ to 8 ), and which also has a stimulatory effect on granulation (Sherman et al. 2000).

Recently, it has been shown that Lucilia sericata larvae secrete various cytokines and tissue growth factors (Sherman et al. 2013). With recent advances in cellular biology and chemistry, the secretory/excretory products of maggots stimulate the proliferation of fibroblasts and endothelial tissue, increases angiogenesis and oxygenation, and enhances fibroblast migration over model wound surfaces (Sherman 2014; Nigam 2016; Nigam and Morgan 2016).

In this study, 20 bacteria were isolated from the ulcers of which 60\% were Gramnegative. Bowler et al. (2001) stated that pressure ulcers mainly harbor diverse and often dense microbial populations involving both aerobic and anaerobic Gram-positive and Gram-negative bacteria especially Staphylococcus and Entrobacter species. Tantawi et al. (2007) has isolated 19 bacteria from 13 diabetic foot ulcers of which the Grampositive were more than Gram-negative. It has been shown that in vivo (Steenvoorde and Jukema 2004) and in vitro (Thomas et al. 1999) trials, maggot therapy was more effective on Gram-positive than Gram-negative bacteria. Steenvoorde and Jukema (2004) stated that the reasons for the faster growth of Gram-negative bacteria during maggot treatment could be attributed to the increase in $\mathrm{pH}$ of the medium exerted by maggots or that the endotoxins produced by Gram-negative bacteria are capable of destroying secretions produced by maggots. The authors concluded that a higher number of maggots is not only needed for a larger wound, or a wound covered with a higher percentage of necrotic tissue, but also for Gram-negative infected wound.

Bacteriological examinations of infected wounds before initiating maggot therapy, followed by subsequent cultures after maggot therapy, have shown that there is a marked decrease in infection (Wolff and Hansson 1999; Bowling et al. 2007). During this study, maggot therapy was associated with marked antimicrobial activity. One or two cycles of maggots were able to reduce the bacterial burden of each ulcer to less than the $10^{5}$ threshold which facilitates natural healing (Schultz et al. 2003). Tantawi et al. (2007) have found that one cycle of maggots was able to decrease the bacterial load of all diabetic foot ulcers under investigation to less than $10^{5}$ $\mathrm{CFU} / \mathrm{ml}$.

It has been now evident that medicinal maggots disinfect the wounds by three 
methods. First, the movement and irritation caused by larvae ingesting liquefied necrotic tissue promote the formation of a serious exudate by the wound. This causes continuous wound lavage and dilution of bacterial concentration (Mumcuoglu 2001). Second, the larvae ingest bacteria that are then killed pass through their digestive tract (Mumcuoglu et al 2001). Third, the larvae secrete/excrete antibacterial compounds on the wound bed (Sherman 2014; Nigam 2016).

During this study, no complications related to maggot therapy were observed. All patients enrolled in this study were accepted to undergo maggot therapy and did not complain of any major discomfort during the treatment. Patients were easily convinced to undergo maggot therapy by showing them or to their relative photographs of previous treatments or giving them a thorough explanation and appropriate literature about the advantages of this method. Only two patients (14.28\%) complained of pain during treatment with maggots and were treated effectively with oral analgesics. It was also noted that the foul odor which was emanating from the ulcers of all patients has been dramatically reduced after maggot therapy. Similar findings and considerations were noted by Kotb et al. (2002).

\section{Conclusions}

The clinical outcomes (debridement and wound healing) demonstrate that maggot therapy is a rapid, simple, efficient, and costeffective tool in the treatment of pressure ulcers that do not respond to conventional treatment and surgical intervention. The application of disinfected larvae of Lucilia sericata to infected, non-healing pressure ulcers of stage III and stage IV resulted in the rapid removal of necrotic tissue, disinfection, and enhancement of the healing process. All three actions are important in the preparation of the wound bed prior to healing.

Microbiological outcomes demonstrate that maggot therapy is an efficient antimicrobial treatment. Maggots were able to reduce the bacterial load of pressure ulcers below the $10^{5}$ threshold which permits healing through one or two cycles.

Maggot therapy could alleviate the suffering in patients with pressure ulcers in Egypt. These patients represent a frail segment of the population and thus they are good maggot therapy candidates as surgical debridement is not an appropriate method for them. There is an overwhelming and urgent need for maggot therapy in developing countries, with poor medical facilities, to improve wound care. 


\section{Study limitation}

As a result of the increased mortality rate of the patients and deteriorations of their conditions, this was led to a decrease in the number of patients selected.

Table 1. Demographic and clinical characteristics of 14 patients with 14 pressure ulcers enrolled in maggot therapy

Age (years)

$\operatorname{Sex}(n)$

Male

Female

Underlying medical conditions (n)

Cerebral vascular stroke

Diabetes mellitus

Chronic obstructive pulmonary disease

Laboratory investigations

Hemoglobin $(\mathrm{g} / \mathrm{dl})$

Male

Female

Albumin (g/dl)

Duration of hospitalization (weeks)
$43.35 \pm 4.18(18-81)$

10

4

6

9

$08.67 \pm 1.925(6.5-11)$

$02.54 \pm 79.77(2-3.1)$

$11.28 \pm 12.24(0.7-49.1)$

Data are means \pm SD (range), unless otherwise specified. 
Table 2. Characteristics of 14 pressure ulcers belonging to 14 patients before maggot therapy

Surface area $\left(\mathrm{cm}^{2}\right)$

Circumference $(\mathrm{cm})$

Surface area of devitalized tissue $\left(\mathrm{cm}^{2}\right)$

$\%$ of devitalized tissue

Age (weeks)

Staging* (n)

Stage III

Stage IV

Anatomical location (n)

Sacrum

Rt ischial

4

Conventional treatment (n)

Saline wet-to-dry gauze dressing, Betadine

Systemic antibiotics

Sharp debridement

Topical antimicrobial agents

10

14

14

6

10
$90.70 \pm 41.38$ (28.6-154)

$30.35 \pm 07.34$ (17-38)

$58.81 \pm 42.33(8.25-131.25)$

$61.73 \pm 30.38(18.5-100)$

$09.78 \pm 04.07(2-15)$

Data are means \pm SD (range), unless otherwise specified.

*Ulcers were staged according to NPUAP (2001). 
Table 3. Clinical outcomes of debridement of 14 pressure ulcers belonging to 14 patients undergone maggot therapy

\begin{tabular}{ll}
\hline \hline The initial surface area of devitalized tissue $\left(\mathrm{cm}^{2}\right)$ & $58.81 \pm 42.33(8.25-131.25)$ \\
$\%$ of the initial surface area of devitalized tissue & $61.73 \pm 30.38(18.5-100)$ \\
Surface area of devitalized tissue $\left(\mathrm{cm}^{2}\right)$ & $15.35 \pm 13.21(0-40)$ \\
$\%$ of surface area of devitalized tissue & $20.21 \pm 17.86(0-69.8)$ \\
Duration until complete debridement (weeks) & $1.5 \pm 0.51(1-2)$ \\
Decrease of surface area of devitalized tissue per week $\left(\mathrm{cm}^{2} / \mathrm{w}\right)$ & 28.97 \\
$\%$ Decrease in surface area of devitalized tissue per week $(\% / \mathrm{w})$ & 27.68 \\
No. of maggot therapy cycles & $1.5 \pm 0.51(1-2)$ \\
No. $(\%)$ of ulcers completely debrided & $3(21.42)$ \\
No. $(\%)$ of ulcers with $>50 \%$ of debridement & $9(64.28)$
\end{tabular}

Data are means \pm SD (range), unless otherwise specified.

Table 4. Quality of wound bed of 14 pressure ulcers belonging to 14 patients who undergone maggot therapy.

The initial surface area of granulation tissue $\left(\mathrm{cm}^{2}\right)$

$16.03 \pm 22.97(0-80)$

Surface area of granulation tissue after maggot therapy $\left(\mathrm{cm}^{2}\right)$

$55.86 \pm 33.90(7.37-116)$

Duration of therapy (weeks)

$2.14 \pm 02.41(1-10)$

No. (\%) of ulcers with $>50 \%$ of their size covered by granulation tissue

$9(64.28)$

Data are means \pm SD (range), unless otherwise specified. 
Table 5. Isolated bacteria from 14 pressure ulcers belonging to 14 patients

Gram-positive

Frequency of appearance

a. Aerobic

- Corynebacterium sp.

- Micrococcus sp.

- Staphylococcus aureus 5

- Staphylococcus Coag. -ve 2

- Streptococcus epidermidis 6

- Streptococcus pyogenes 3

- Enterococcus faecalis* 5

b. Anaerobic

- Peptostreptococcus sp.

Gram-negative

a. Aerobic \& facultative

- Acinetobacter sp.

- Citrobacter sp.

- Enterobacter aerogenes

- Enterobacter cloacae

- Escherichia coli

- Klebsiella sp

- Proteus mirabilis

6

- Proteus vulgaris

1

- Pseudomonas aeruginosa 4

- Serratia liquefaciens

b. Anaerobic

- Bacteroides sp. 6

- Propionibacterium sp. 3

*(Previously Group D Streptococcus)

Coag $+\mathrm{ve}=$ coagulase positive, Coag $-\mathrm{ve}=$ coagulase negative . 
Table 6. Number of bacterial strains isolates from each of 14 pressure ulcers belonging to 14 patients

\begin{tabular}{|c|c|}
\hline Ulcer & Isolated bacteria \\
\hline
\end{tabular}

1 Staphylococcus aureus, Streptococcus epidermidis, Streptococcus 6 pyogenes, Klebsiella sp., Pseudomonas aeruginosa, Bacteroides sp.

2 Streptococcus epidermidis. Enterobacter aerogenes, Proteus mirabilis, Pseudomonas aeruginosa, Serratia liquefaciens, Bacteroides sp.

3 Corynebacterium sp., Staphylococcus aureus, Streptococcus epidermidis, Bacteroides sp, Peptostreptococcus sp..

4 Streptococcus pyogenes, Enterococcus faecalis, Enterobacter cloacae, Escherichia coli

5 Micrococcus sp., Streptococcus epidermidis, Proteus mirabilis, Propionibacterium sp.

6 Staphylococcus aureus, Staphylococcus Coag. -ve, Enterobacter aerogenes

7 Corynebacterium sp., Enterococcus faecalis, Enterobacter cloacae, Escherichia coli.

$8 \quad$ Corynebacterium sp., Streptococcus epidermidis, Acinetobacter $\mathrm{sp} . \quad 3$

$9 \quad$ Staphylococcus Coag. - ve, Streptococcus pyogenes, Escherichia coli, $\quad 6$ Proteus mirabilis, Bacteroides sp, Peptostreptococcus sp.

10 Staphylococcus aureus, Acinetobacter sp., Proteus vulgaris, Propionibacterium sp.

11 Micrococcus sp., Enterococcus faecalis, Enterobacter cloacae, Escherichia coli, Proteus mirabilis, Proteus vulgaris, Bacteroides sp.

12 Streptococcus epidermidis, Enterobacter aerogenes, Pseudomonas aeruginosa.

13 Staphylococcus aureus, Enterococcus faecalis, Enterobacter cloacae, Escherichia coli, Proteus mirabilis, Propionibacterium sp. 
14 Enterococcus faecalis, Citrobacter sp., Escherichia coli, Pseudomonas

5 aeruginosa, Bacteroides sp.

Table 7. Bacterial burden of 14 pressure ulcers belonging to 14 patients before and after maggot therapy

\begin{tabular}{|c|c|c|c|c|c|c|}
\hline \multirow{2}{*}{ Ulcer } & \multicolumn{4}{|c|}{ Bacterial burden (CFU/ml) } & \multicolumn{2}{|c|}{ Fold of decrease } \\
\hline & Before MT1 & After MT1 & Before MT2 & After MT2 & MT1 & MT2 \\
\hline 1 & $7.40 \mathrm{E}+08$ & $2.01 \mathrm{E}+04$ & - & - & $3.68 \mathrm{E}+04$ & \\
\hline 2 & $9.20 \mathrm{E}+07$ & $1.80 \mathrm{E}+04$ & - & - & $5.11 \mathrm{E}+03$ & \\
\hline 3 & $3.90 \mathrm{E}+08$ & $5.50 \mathrm{E}+03$ & - & - & $7.09 \mathrm{E}+04$ & \\
\hline 4 & $1.20 \mathrm{E}+09$ & $6.70 \mathrm{E}+02$ & - & - & $1.79 \mathrm{E}+06$ & _ \\
\hline 5 & $6.30 \mathrm{E}+07$ & $7.40 \mathrm{E}+03$ & - & - & $8.51 \mathrm{E}+03$ & - \\
\hline 6 & $7.10 \mathrm{E}+05$ & $3.30 \mathrm{E}+04$ & - & - & 2.15E+01 & - \\
\hline 7 & $4.40 \mathrm{E}+07$ & $8.50 \mathrm{E}+02$ & - & - & $5.18 \mathrm{E}+04$ & - \\
\hline 8 & $8.40 \mathrm{E}+06$ & $4.20 \mathrm{E}+02$ & - & - & $2.00 \mathrm{E}+04$ & - \\
\hline 9 & $6.80 \mathrm{E}+05$ & $2.80 \mathrm{E}+03$ & $1.20 \mathrm{E}+05$ & $2.80 \mathrm{E}+03$ & $2.43 \mathrm{E}+02$ & $4.29 \mathrm{E}+01$ \\
\hline 10 & $9.10 \mathrm{E}+06$ & $8.10 \mathrm{E}+04$ & $3.90 \mathrm{E}+06$ & $2.60 \mathrm{E}+04$ & $1.12 \mathrm{E}+02$ & $1.50 \mathrm{E}+02$ \\
\hline 11 & $4.60 \mathrm{E}+08$ & $7.20 \mathrm{E}+03$ & $4.80 \mathrm{E}+04$ & $4.50 \mathrm{E}+02$ & $6.39 \mathrm{E}+04$ & $1.07 \mathrm{E}+02$ \\
\hline 12 & $2.90 \mathrm{E}+09$ & $6.30 \mathrm{E}+02$ & $7.10 \mathrm{E}+07$ & $1.60 \mathrm{E}+03$ & $4.60 \mathrm{E}+06$ & $4.44 E+04$ \\
\hline 13 & $5.70 \mathrm{E}+08$ & $4.80 \mathrm{E}+03$ & $6.30 \mathrm{E}+06$ & $2.20 \mathrm{E}+04$ & $1.19 \mathrm{E}+05$ & $2.86 \mathrm{E}+02$ \\
\hline 14 & $3.30 \mathrm{E}+08$ & $8.70 E+04$ & $2.90 \mathrm{E}+05$ & $5.20 \mathrm{E}+03$ & $3.79 \mathrm{E}+03$ & $5.58 \mathrm{E}+01$ \\
\hline $\begin{array}{c}\text { Means } \\
\pm \\
\text { SD }\end{array}$ & $\begin{array}{c}4.86 \mathrm{E}+08 \\
\pm \\
779501673.9\end{array}$ & $\begin{array}{c}1.92 \mathrm{E}+04 \\
\pm \\
29000.81364\end{array}$ & $\begin{array}{c}5.61 \mathrm{E}+05 \\
\pm \\
28229993.42\end{array}$ & $\begin{array}{c}1.36 \mathrm{E}+07 \\
\pm \\
11278.37533\end{array}$ & $\begin{array}{c}4.84 \mathrm{E}+05 \\
\pm \\
1274542.528\end{array}$ & $\begin{array}{c}7.50 \mathrm{E}+03 \\
\pm \\
18074.04166\end{array}$ \\
\hline
\end{tabular}

Data are means \pm SD (range), unless otherwise specified.

MT1= first maggot therapy cycle.

MT2= second maggot therapy cycle. 

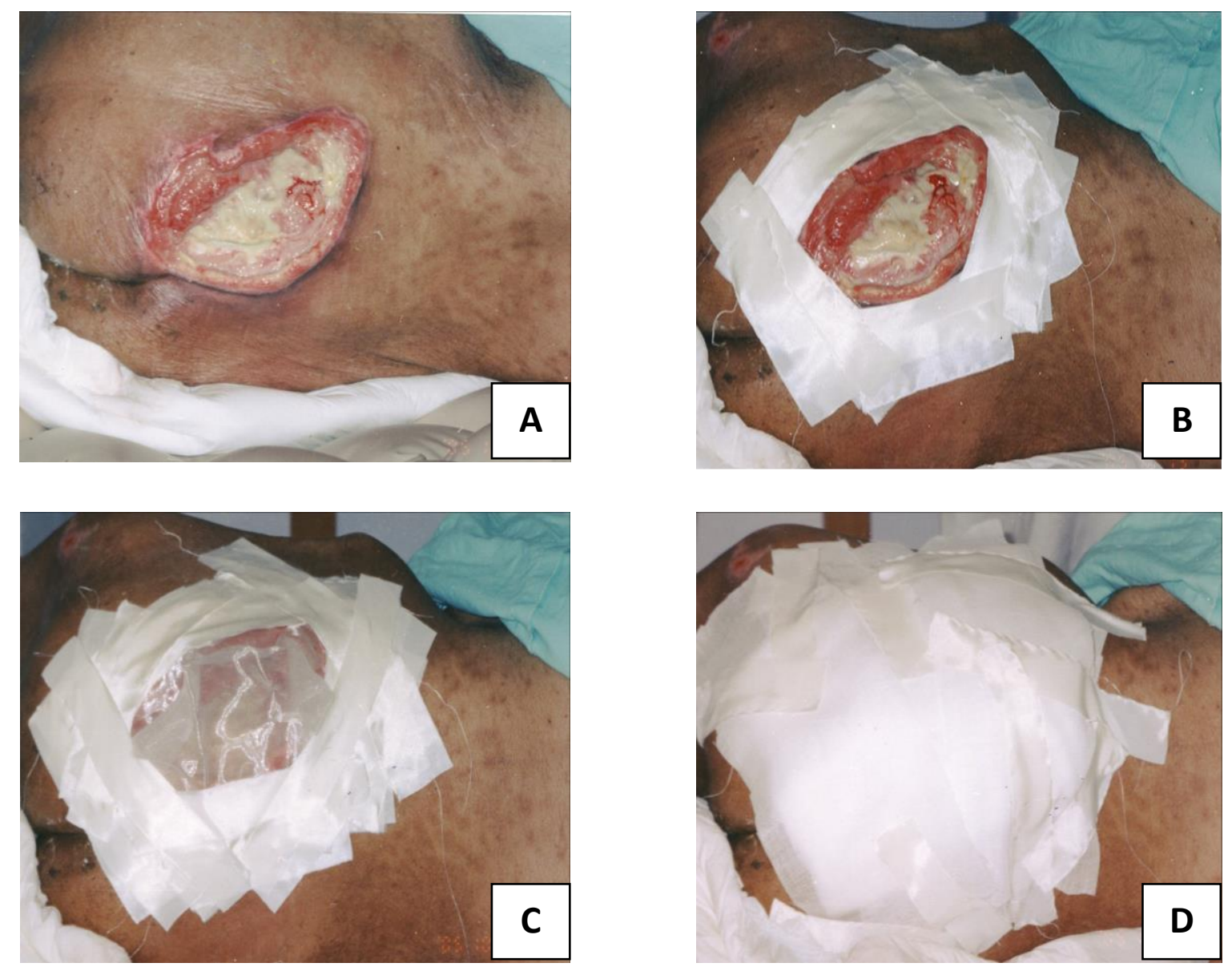

Fig. 1. Method of application of maggot therapy dressing to the wound. A) Sloughy sacral ulcer; B) Adhesive silk plaster applied to the edges of pressure ulcer to protect the intact skin from the proteolytic enzymes secreted by maggots and to form the initial dressing; C) Nylon mesh applied to pressure ulcer to form a cage housing the maggots. Note the aggregation of young instars of Lucilia sericata beneath the mesh; D) Gauze sheet covering the mesh to strengthen the dressing, absorb wound exudate, and give an acceptable appearance of the treatment. 


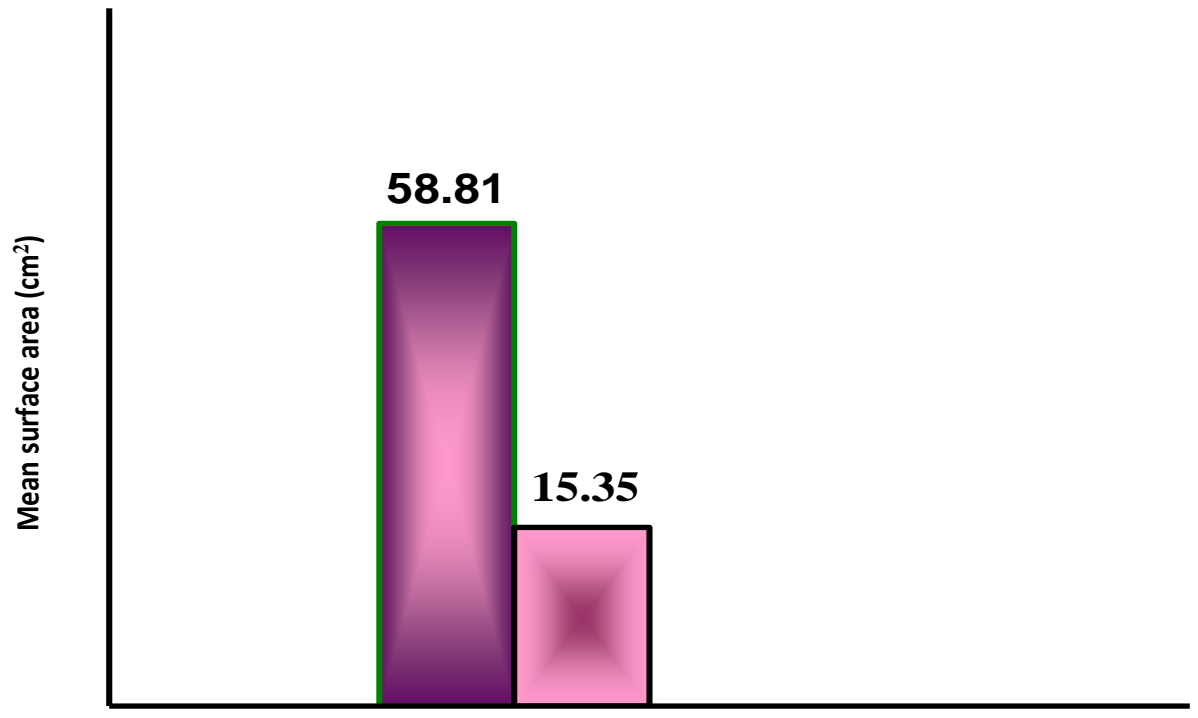

$\square$ Before therapy $\square$ After therapy

Fig. 2. Mean surface area of devitalized tissue of 14 pressure ulcers before and after maggot therapy. 


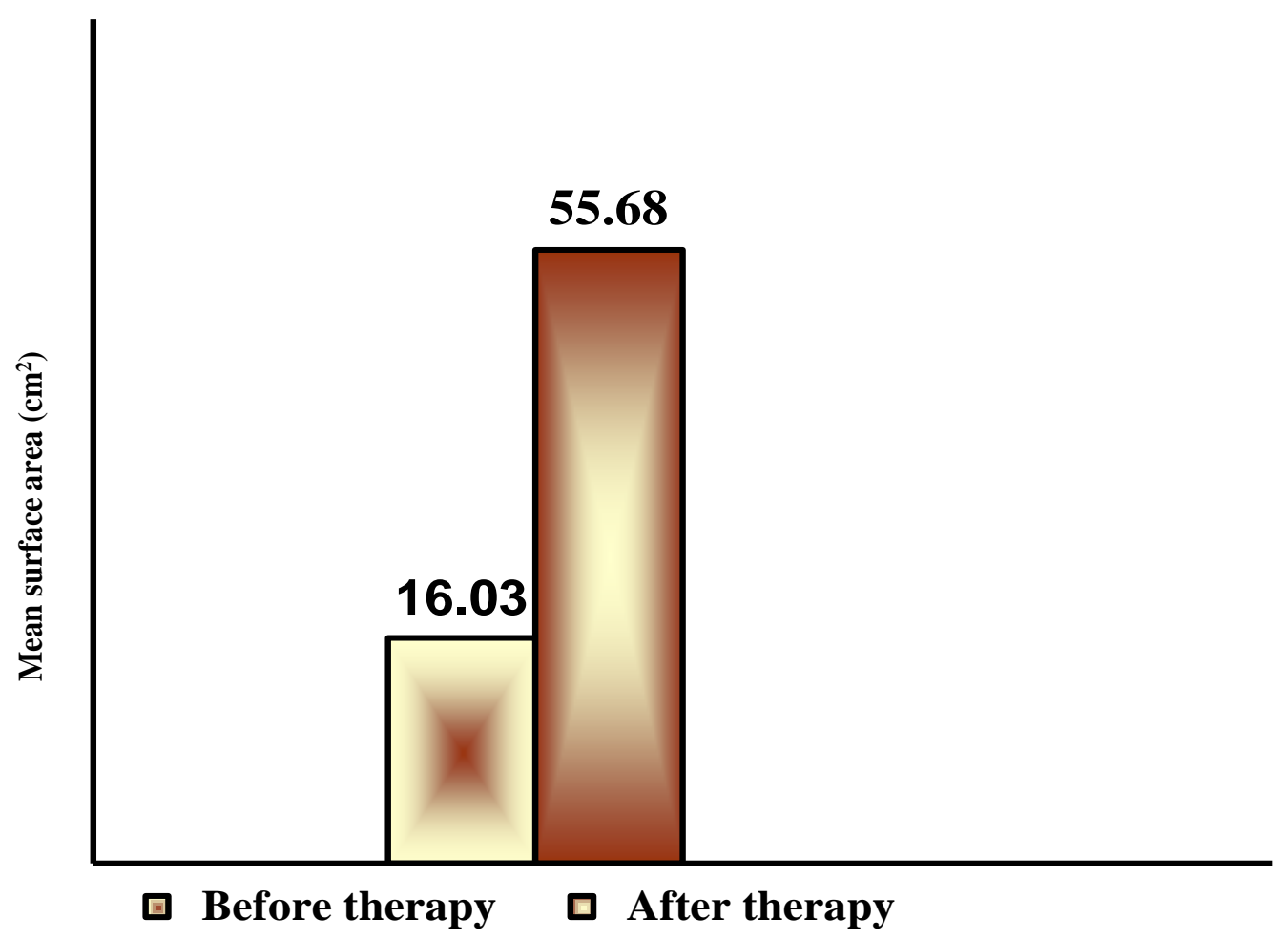

Fig. 3. Mean

surface area of granulation tissue of 14 pressure ulcers before and after maggot therapy. 

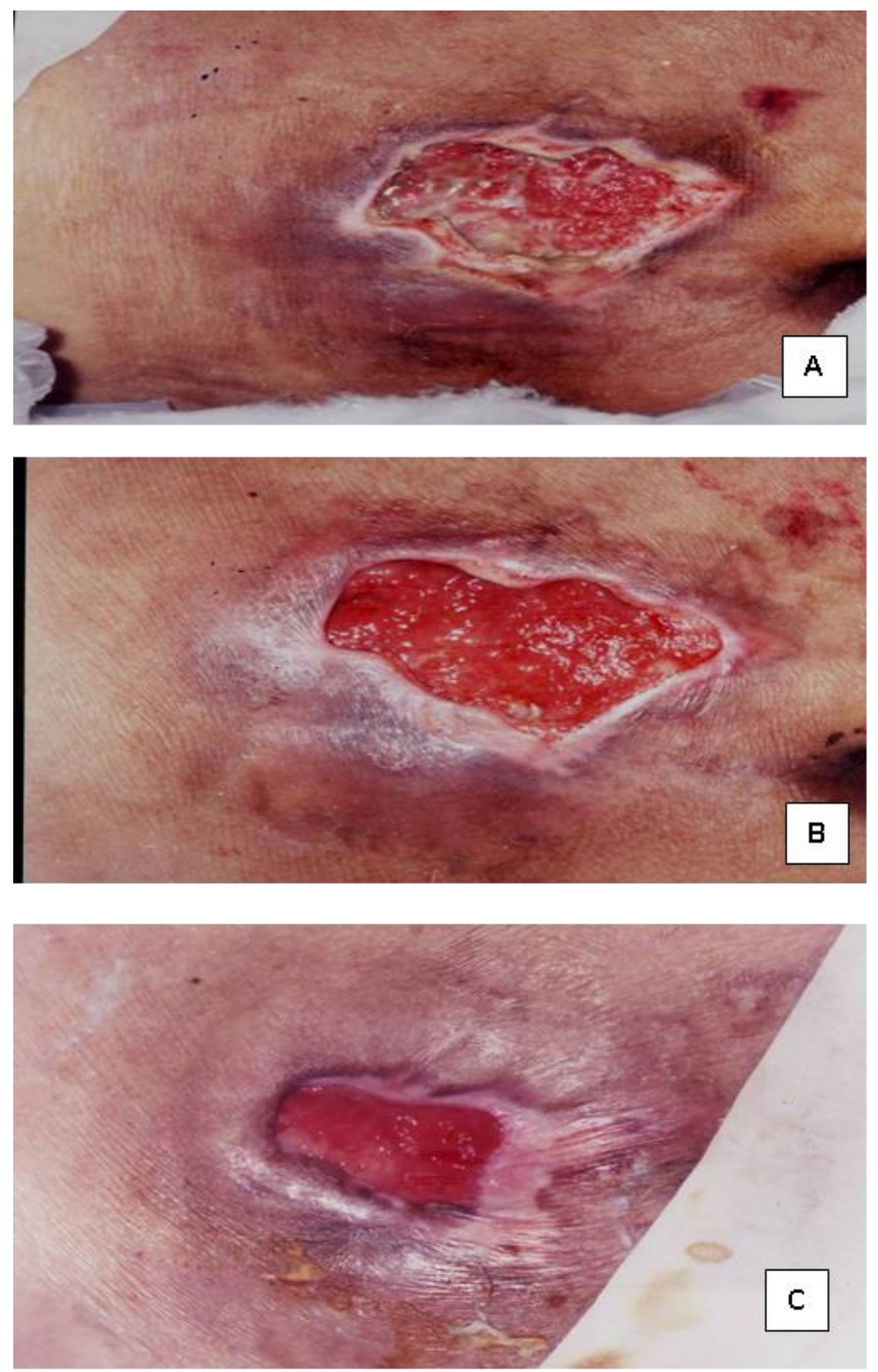

Fig. 4. Sacral pressure ulcer. A) before maggot therapy; B) after one week; and C) after 4 weeks of maggot therapy. 

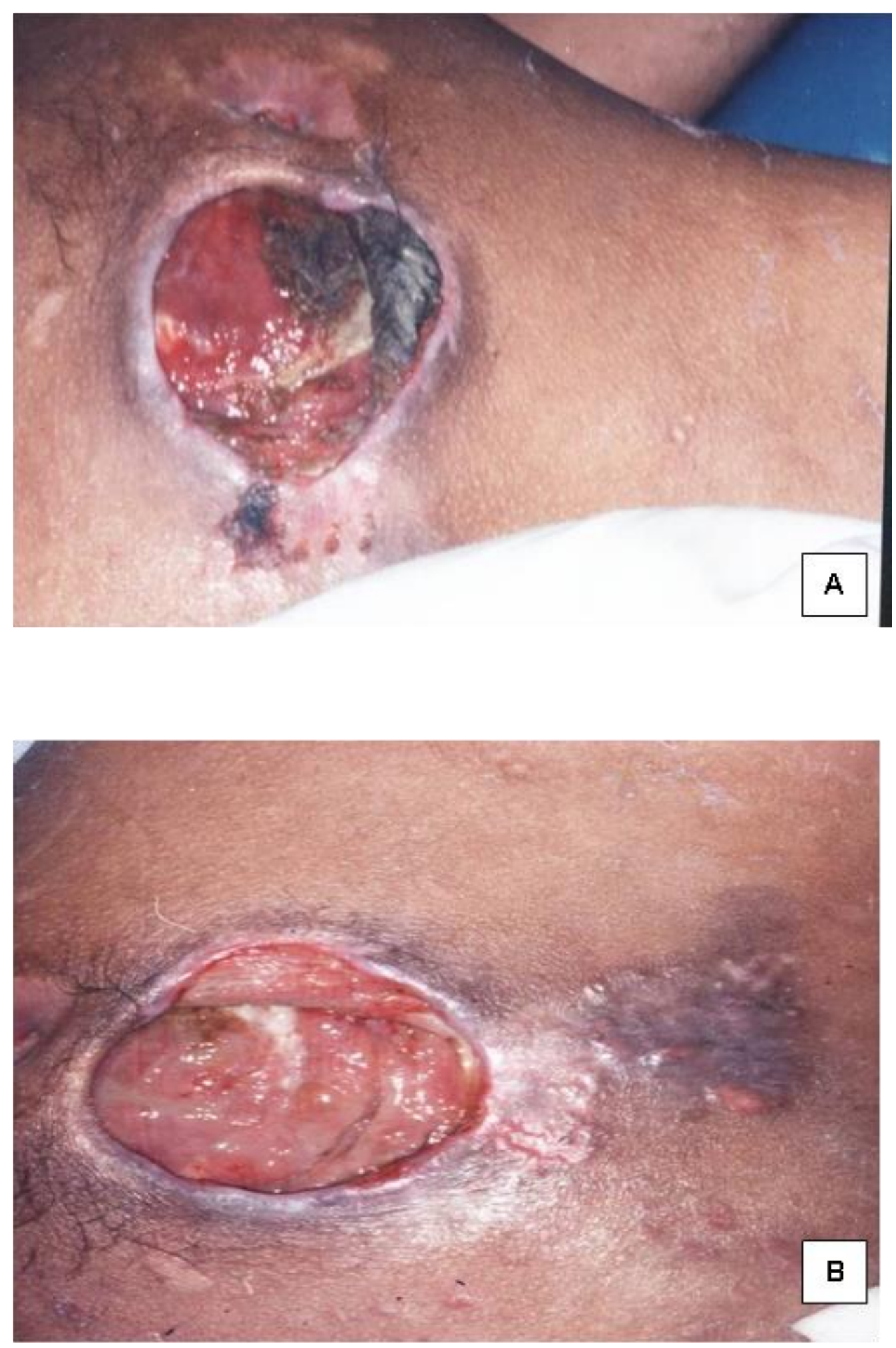

Fig. 5. Ischial pressure ulcer. A) before maggot therapy and B) after one week of maggot therapy. 


\section{References}

Amir, Y., Lohrmann, C., Halfens, R.J.G., and Schols, J.M.G.A. 2017. Pressure ulcers in four Indonesian hospitals: prevalence, patient characteristics, ulcer characteristics, prevention and treatment. Int. Wound J. 14:184-193.

Atlas, R.M. 1997. Handbook of microbiological media. 2nd ed. L.C. Parks (Ed.). CRC Press, Boca Raton, Florida.

Allman, R.M., Goode, P.S., Patrick, M.M., Burst, N., and Bartolucci, A.A. 1995. Pressure ulcer risk factors among hospitalized patients with activity limitation. J. Am. Med. Assoc. 273 (11): 865-870.

Allman, R.M., Goode, P.S., Burst, N., Bartolucci, A.A., and Thomas, D.R. 1999. Pressure ulcers, hospital complications, and disease severity: impact of hospital costs and length of stay. Adv. Skin Wound Care 12: 2230.

Bergstrom, N., Allman, R.M., Alvarez, O.M., Bennett, M.A., Carlson, C.E., et al. 1994. Treatment of pressure ulcers. Clinical practice guideline, No. 15. AHCPR Publication No. 950652. Rockville, MD. U.S. Department of Health and Human Services. Public Health service, Agency for Health Care Policy and Research.

Bowler, P.G., Duerden, B.I., and Armstrong, D.G. 2001. Wound microbiology and associated approaches to wound management. Clin. Microbiol. Rev. 14: 244-269.

Bowling, F.L., Salgami, E.V., and Boulton, A.J.M. 2007. Larval therapy: a novel treatment in eliminating methicillin-resistant Staphylococcus aureus from diabetic foot ulcers. Diabetes Care 30: 370-371.

Bryant, T.N. 2004. Probabilistic identification of bacteria software. Version 1.9.2. University of Southampton. http://www.som.soton.ac.uk/staff/tnb/pib.htm. Davies, C.E., Woolfrey, G., Hogg, N., Dyer, J., Cooper, A., et al. 2015. Maggots as a wound debridement agent for chronic venous leg ulcers under graduated compression bandages: a randomized controlled trail. Phlebology 30: 693-699.

Dharmarajan, T.S. and Ugalino, J.T. 2002. Pressure ulcers: clinical features and management. Hosp. Phys. 38: 64-71. 
Gilead, L., Mumcuoglu, K.Y., and Ingber, A. 2012. The use of maggot debridement therapy in the treatment of chronic wounds in hospitalized and ambulatory patients. J. Wound Care 21: 78-85.

Hampton, S. 2005. Death by pressure ulcer: being held to account when ulcers develop. J. Commu. Nurs. 19: 26-27.

Kirshen, C., Woo K., Ayello, E.A., and Sibbald, R.G. 2006. Debridement: a vital component of wound bed preparation. Adv. Skin Wound Care 19 (9): 506-517.

Kotb, M.M., Tantawi, T.I., Gohar, Y.M., Beshara, F.M.S., and Fatthalah, S.M.S.A. 2002. The medicinal use of maggots in the management of venous stasis ulcers and diabetic foot ulcers. Bulletin of Alexandria Faculty of Medicine 38 (2): 205-214.

Mirabzadeh, A., Ladani, M.J., Imani, B., Rosen, S.A.B., and Sherman, R.A. 2017. Maggot therapy for wound care in Iran: a case series of the first 28 patients. J. Wound Care 26: 137-143.

Mumcuoglu, K.Y. 2001. Clinical applications for maggots in wound care. Am. J. Clin. Dermatol. 2: 219-227.
Mumcuoglu, K.Y., Ingber, A., Gilead, L., Stessman, J., Friedmann, R., et al. 1998. Maggot therapy for the treatment of diabetic foot ulcers. Diabetes Care 21: 2030-2031.

Mumcuoglu, K.Y., Ingber, A., Gilead, L., Stessman, J., Friedmann, R., et al. 1999. Maggot therapy for the treatment of intractable wounds. Int. J. Dermatol. 38: 623-627.

Mumcuoglu, K.Y., Miller, J., Mumcuoglu, M., Friger, M., and Tarshis, M. 2001. Destruction of bacteria in the digestive tract of the maggot of Lucilia sericata (Diptera: Calliphoridae). J. Med. Entomol. 38: 161-166.

Niezgoda, J.A. and Mendez-Eastman, S. 2006. The effective management of pressure ulcers. Adv. Skin Wound Care 19 (1 Suppl): 3-15.

Nigam, Y. 2016. Advances in myiasis treatment. Health Care: Current Reviews 4: 161. doi: 10.4172/2375-4273.1000161.

Nigam, Y. and Morgan, C. 2016. Does maggot therapy promote wound healing? The clinical and cellular evidence. JEADV 30: 776-782.

NPUAP (National Pressure Ulcer Advisory Panel). 2001. Pressure ulcers in America: prevalence, incidence, and implications for the future. An executive summary of the national 
pressure ulcer advisory panel monograph. Adv.

Skin Wound Care 14: 208-215.

Schultz, G.S., Sibbald, R.G., Falanga, V., Ayello, E.A., Dowsett, C., et al. 2003. Wound bed preparation: a systemic approach to wound management. Wound Rep. Reg. 11 (Suppl 1): $1 \mathrm{~S}-28 \mathrm{~S}$.

Sherman, R.A. 2002. Maggot versus conservative debridement therapy for the treatment of pressure ulcers. Wound Rep. Reg. 10: $208-214$.

Sherman, R.A. 2003. Maggot therapy for treating diabetic foot ulcers unresponsive to conventional therapy. Diabetes Care 26: 446451.

Sherman, R.A. 2014. Mechanisms of maggotinduced wound healing: what do we know, and where do we go from here? Evidence-Based Complementary and Alternative Medicine, Volume 2014, Article ID 592419, 13 pages, http://dx.doi.org/10.1155/2014/592419.

Sherman, R.A., Wyle F., and Vulpe, M. 1995. Maggot therapy for treating pressure ulcers in spinal cord injury patients. J. Spinal Cord Med. 18: 71-74.
Sherman, R.A., Tran, J.M., and Sullivan, R. 1996. Maggot therapy for venous stasis ulcers. Arch. Dermatol. 132: 254-256.

Sherman, R.A., Hall, M.J.R., and Thomas, S. 2000. Medicinal maggots: an ancient remedy for some contemporary afflictions. Annu. Rev. Entomol. 45: 55-81.

Sherman, R.A., Mumcuoglu, K.Y., Grassberger, M., and Tantawi, T.I. 2013. Maggot therapy, pp. 5-29. In: M. Grassberger, R.A. Sherman, O.S. Gileva, C.M.H. Kim, and K.Y. Mumcuoglu (Eds), Biotherapy - History, Principles and Practice: a practical guide to the diagnosis and treatment of disease using living organisms. Springer, Dordrecht, Netherlands.

Sokal, R.P. and Rohlf, F.J. 1981. Biometry- the principles and practice of statistics in biological research, 2nd ed. W.H. Freeman and Company, New York, NY.

Spilsbury, K., Nelson, A., Cullum, N., Iglesias, C., Nixon, J., and Mason, S. 2007. Pressure ulcers and their treatment and effects on quality of life: hospital inpatient perspectives. J. Adv. Nurs. 57(5): 494-504.

Steenvoorde, P. and Jukema, G.N. 2004 The antimicrobial activity of maggots:in-vivo results. J. Tissue Viabil. 14: 97-101. 
Tachibana, T., Imafuku, S., Irisawa, R., Ohtsuka, M., Kadono,T., et al. 2016. The wound/burn guidelines- 2: Guidelines for the diagnosis and treatment for pressure ulcers. J. Dermatol. 43: 469-506.

Tantawi, T.I., Gohar, Y.M., Kotb, M.M., Beshara, F.M., and El-Naggar, M.M. 2007. Clinical and microbiological efficacy of MDT in the treatment of diabetic foot ulcers. J. Wound Care 16(9): 379-383.

Tanyuksel, M., Araz, E., Dundar, K., Uzun, G., Gumus, T., et al. 2005. Maggot debridement therapy in the treatment of chronic wounds in a military hospital setup in Turkey. Dermatology 210: 115-118.

Thomas, S. 2006. Cost of managing chronic wounds in the U.K., with particular emphasis on maggot debridement therapy. J. Wound Care 15: 465-469.

Thomas, S., Jones, M., and Shutler, S., and Jones, S. 1996. Using larvae in modern wound management. J. Wound Care 5: 60-69.

Thomas, S., Andrew, A.M., Hay, N.P., and Bourgoise, S. 1999. The anti-microbial activity of maggot secretions: results of a preliminary study. J. Tissue Viabil. 9: 127-132.

Trudgian, J. 2002. Evaluating the benefits of larval therapy. Nurs. Stand. 16 (22): 65-73.

Wayman, J., Nirojogi, V., Walker, A., Sowinski, A., and Walker, M.A. 2000. The cost effectiveness of larval therapy in venous ulcers. J. Tissue Viabil. 10: 91-94.

Whitney, J., Phillips, L., Aslam, R., Barbul, A., Gottrup, F., et al. 2006. Guidelines for the treatment of pressure ulcers. Wound Rep. Reg. 14: 663-679.

Wolff, H. and Hansson, C. 1999. Larval therapy for a leg ulcer with methicillin-resistant Staphylococcus aureus. Act. Dermatol. Venerol. 79: 320-335.

Wolff, H. and Hansson, C. 2003. Larval therapy- an effective method of ulcer debridement. Clin. Exp. Dermatol. 28: 134-137.

Zumpt, F. 1965. Myiasis in man and animals in the Old World. Butterworths, London. 